\title{
THE DIFFERENTIAL DIAGNOSIS OF TUMOUR CELLS IN CIRCULATING BLOOD
}

\author{
BY \\ R. F. ALEXANDER AND A. I. SPRIGGS \\ From the Churchill Hospital, Headington, Oxford
}

(RECEIVED FOR PUBLICATION FEBRUARY 20, 1960)

\begin{abstract}
White-cell concentrates were made by a dextran sedimentation technique from the blood of 140 cases of malignant disease and 60 controls. The slides were searched for tumour cells and for other unusual cells with which they might be confused. Several million white cells were scanned in the slides from each case.

Acceptable tumour cells were identified in the blood of seven patients, none of whom survived for more than a few months. These cells are illustrated, as well as various other cell types which may have been confused with malignant cells in the past. It is concluded that the cytology of white cell concentrates should be further explored before statistics about the occurrence of circulating tumour cells are accepted.
\end{abstract}

Metastasis of malignant tumours by way of the blood stream is common, but until the last five years there were very few descriptions of the isolation of tumour cells from the circulating blood (Marcus, 1919; Jonescu, 1931; Pool and Dunlop, 1934). It was usually thought that metastases were thrown off intermittently and in small numbers so that there was little likelihood of finding them in a random blood sample.

An exception is provided by the malignant conditions of the haemopoietic system-leukaemia, reticulosarcoma, multiple myeloma - which will not be considered here. Another is neuroblastoma, which occasionally mimics an acute leukaemia (Undritz, 1948, and in the Sandoz atlas; Christenson, Ultmann, and Mohos, 1956; Okinaka, Nakao, Kinugasa, Takaku, and Ohtsuki, 1956).

With the introduction of effective methods of separating the red and white cells, new attempts have been made to identify circulating cancer cells. Reports have now come from various centres claiming to have found such cells in a surprisingly high proportion of cases of malignant disease, ranging from 16 to $59 \%$ (Engell, 1955, 1959; Fisher and Turnbull, 1955; Moore, Sandberg, and Schubarg, 1957; Roberts, Watne, McGrath, McGrew, and Cole, 1958; Pruitt, Hilberg, and Kaiser, 1958; Fletcher and Stewart, 1959; Reiss, 1959).
After practically a century of morphologica haematology it might be thought that all the typers of cell occurring in the blood would already be well known. It turns out, however, that this is not the case, and the new techniques of white cell concentration are beginning to reveal a remarkable variety of non-malignant cells which are seldom or never figured in atlases of the blood. Unfortunately the statistics of the occurrence of supposedly malignant cells in the blood have been compiled and published before, and not after, a thorough study of the other lesser-known cells which might cause confusion, and it seems very likely that malig nant cells have been overdiagnosed for this reason

Several of the authors recommend techniques which have not been extensively used in the past for the study of blood or bone marrow. The Papanicolaou method, for instance, does not seem to us to have any advantage in this field over the Romanowsky stains which are universally used in haematological diagnosis.

We hope in this paper to help to remedy the position by illustrating a variety of different nonmalignant cells, some of which are of known origin and others' unknown, as well as some which we consider to be acceptable tumour cells. The reader is also referred to Sandberg, Moore, and Schubarg (1959) for illustrations of certain non-malignant cells found in the blood. 


\section{Material and Technique}

Two hundred and fifty blood samples vee:e examined from 200 persons. One hundred and forty of these were cases of malignant disease, mostly advanced; and 60 were eitrer normal or suffered from other diseases. A particular effort was made to find patients in whom abnormal cells might be expected, for instance, those with leuco-erythroblastic anaemia and with terminal illnesses. Most of the samples were from the antecubital vein, but 45 samples were taken in the operating theatre from veins draining either malignant tumours or other " control" lesions.

The method used was similar to that of Sandberg and Moore, but we found that the use of dextran instead of fibrinogen solution avoided the formation of lumps of fibrin with adherent white cells or platelets.

Blood, $4 \mathrm{ml}$., was mixed with $1 \mathrm{ml}$. of $6 \%$ dextran solution in $0.9 \%$ saline, containing 45 units of heparin per ml., in a siliconed tube. This was left undisturbed for 20 to $30 \mathrm{~min}$., by which time the red cells had sedimented. The supernatant fluid was transferred to a siliconed conical centrifuge tube and centrifuged at less than 1,000 r.p.m. for 10 minutes. The whole of the deposit was then spread on a series of slides by the method used for making blood films. Usually about twel e films were made. All of these were fixed in methyl alcohol, stained with May-Grünwald-Giemsa, and mounted in DPX. The whole of every slide was examined under the $16 \mathrm{~mm}$. objective and unusual cells marked and studied under higher powers. By this means an adequate view was obtained of several millions of white cells from each specimen. These cells had suffered no visible alteration from the normal appearances as seen in directly made blood films.

Although the scanning of these films is very laborious, losses of possible tumour cells are minimized. Any further concentration procedures involve not only loss of cells, but deterioration of the cells which remain.

\section{Non-malignant Nucleated Cells Occurring in White Cell Concentrates}

Granular Series.-These are the predominant cells in white cell concentrates and need not be described here. Occasionally myelocytes show defective granulation and, being large, attract attention. Myeloblasts are usually too small to be confused with tumour cells.

Lymphocytes.-Next in frequency to the neutrophil granulocytes, the lymphocytes can hardly be confused with neoplastic cells. A very occasional large form may occur, but rarely reaches the size of the smallest oat cell.

Plasma Cells.-Cells of the plasmacyte series are probably always present. They are familiar to haematologists as "Tirk cells." In direct blood films from normal people only an occasional Türk cell can be found, but they are prominent in white cell concentrates owing to their deep cytoplasmic basophilia. No full description need be given, as there are excellent pictures in the haematological atlases (Undritz, 1952; Osgood and Ashworth, 1937; Moeschlin, 1947; Bessis, 1956).

Turk cells are very variable, both in size and in nuclear chromatin pattern. Some forms have a fine chromatin pattern with distinct nucleoli, and as the nuclear diameter may reach $16 \mu$ or occasionally even more, they can cause confusion to the inexperienced. The cytoplasm invariably shows deep basophilic staining, a feature which is hardly ever found in free tumour cells, so that this is an important differential point (Figs. 1 and 2). They also sometimes show cytoplasmic hyaline droplets (Mott cells or grape cells).

Turk cells have been found in mitosis in many of $t$ e white cell concentrates; in fact it is rare to see division occurring in any other type of cell, e.g., normoblasts, myelocytes, megakaryocytes. The description and illustrations given by Nowell (1960) of dividing cells in cultures from peripheral blood are reminiscent of the same cell type.

Monocytes.-Monocytes are always abundant in white cell concentrates and although there are occasional large forms possessing nucleoli they have not in our experience caused difficulties of identification.

Macrophages.-This name has been applied to monocytes which develop vacuoles and evidence of phagocytosis, and are found in the blood in septicaemia. Cells similar to the alveolar macrophages of the lung have been recorded by Sandberg et al. (1959). We have seen isolated examples of macrophages in blood from a variety of cases, and occasionally their contents have been of a specific kind; for instance, in a case of Gaucher's disease (Fig. 3) these cells contained the characteristic fibrous or crystalline material, and in a case of malignant melanoma with melanosis there were macrophages containing melanin (Goodall, Spriggs, and Wells, 1960).

Megakar jocytes.-The bare nuclei of megakaryocytes are normally present in the blood, but in very small numbers. Using $4 \mathrm{ml}$. volumes we have found a few in all normal samples examined, and their numbers are often increased in disease.

Megakaryocyte nuclei are often seen attached to platelet agglutinates, as shown in Fig. 156 of the Sandoz Atlas of Haematology. They also occur separately, and may be of considerable size with several lobes (Fig. 4). In Papanicolaou preparations they appear markedly hyperchromatic (Fig. 5).

Examples with cytoplasm also occur, but in our experience these have only been found in disease, 


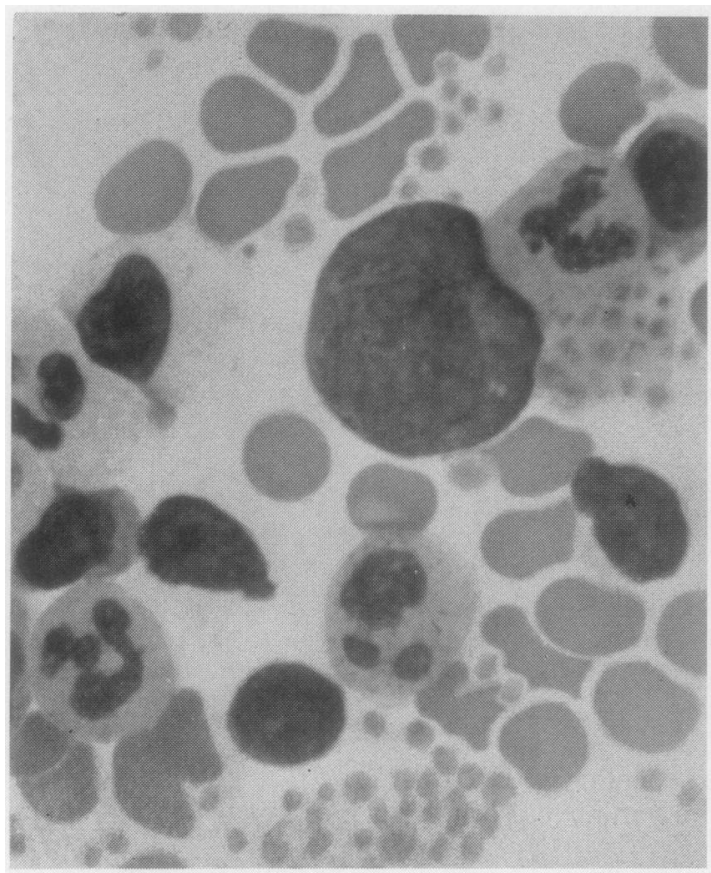

Fig. 1.- “Türk cell” or proplasmacyte. These cells are normally present in the blood, and are remarkable for their deeply basophilic cytoplasm. The example shown has several visible nucleoli. Case of cerebral tumour $(\times 1,300)$.

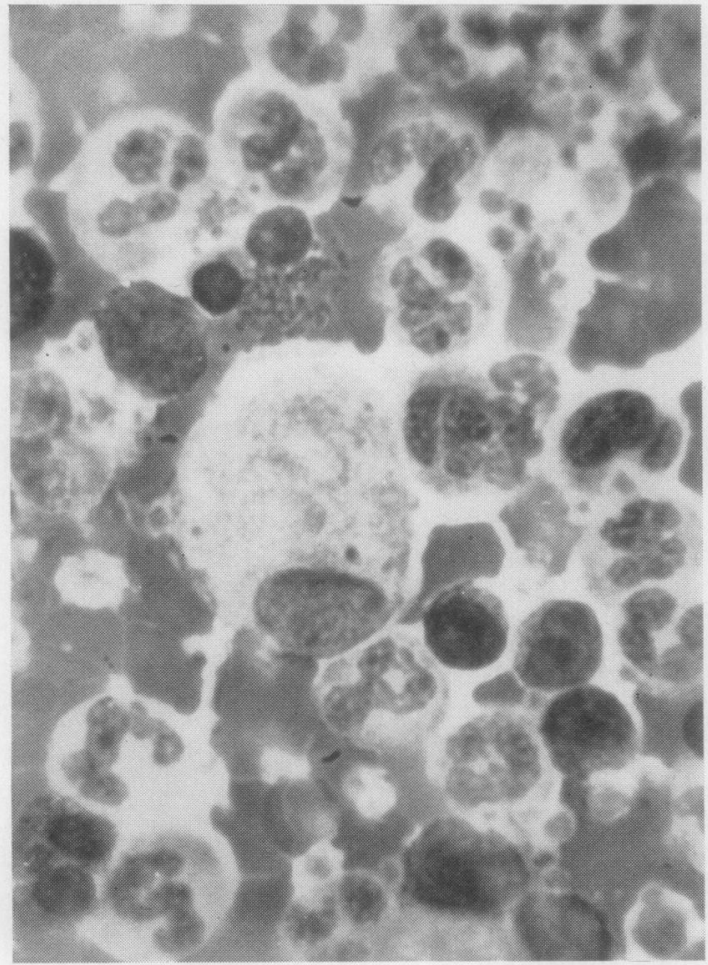

FIG. 3.-Lipid-containing macrophage in venous blood of a case of Gaucher's disease $(\times 1,300)$.

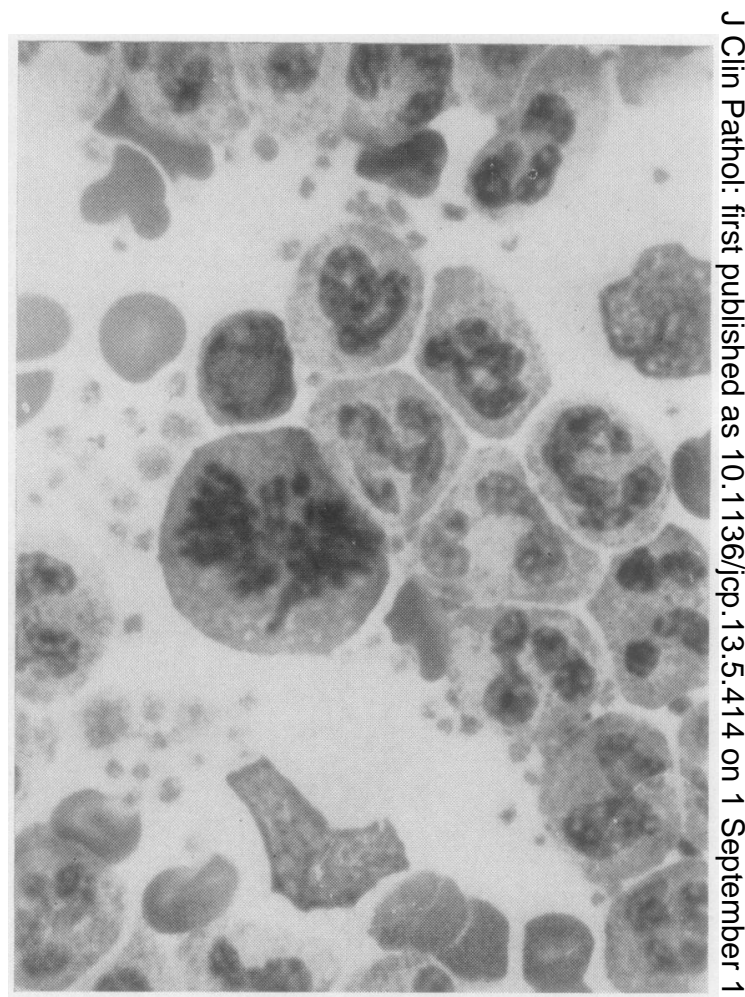

FIG. 2.- "Türk cell" in mitosis. This is seen in many cases whefe $\vec{\theta}$ the plasma cell series are numerous. Same case as Fig. O $(\times 1,300)$.

흘

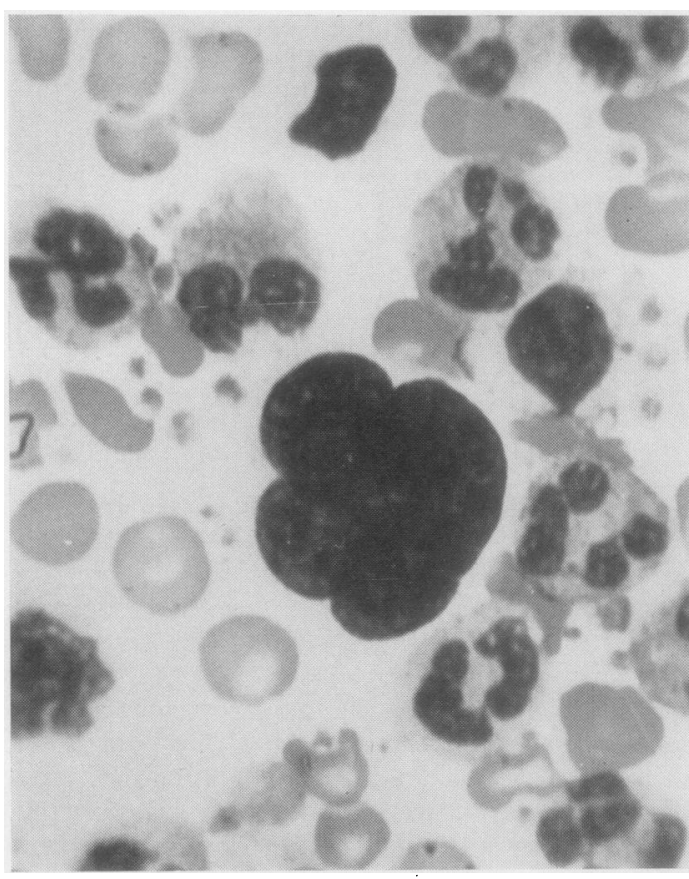

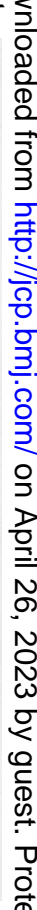

Fig. 4.-Megakaryocyte nucleus in peripheral blood. These have $\overparen{D}$ been found in nearly every sample so far examined, including all $\mathbb{D}$ those taken from healthy subjects. This one is from a case of $\varrho$ carcinoma of the pancreas $(\times 1,300)$. 
for example, in malignant disease and in leucoerythroblastic anaemia (Figs. 6 to 12). Di Guglielmo (1923) illustrated them in chronic myeloid leukaemia. Their morphology is the same as in bone marrow and very large ones are occasionally seen, for instance, we have observed one measuring $50 \mu$ across. In one patient with a leuco-erythroblastic anaemia due to myelosclerosis we found one in mitosis (Fig. 10). Sometimes there is a high nucleo-cytoplasmic ratio, and instead of the usual profuse, pale, violet-stained cytoplasm with eosinophilic granules there is a narrow rim of cytoplasm showing intense basophilia (Figs. 7, 8, and 11). These correspond to the megakaryoblasts illustrated by Bessis (1956) and such cells may well have been confused in the past with tumour cells. It should be emphasized again that deeply basophilic cytoplasm is very uncommon in malignant cells.

Osteoclasts.-Osteoclasts are figured in the Sandoz atlas and by Tischendorf and Heckner (1950).

We have only on one occasion seen a probable osteoclast in the circulating blood (Fig. 13). The cell measured $33 \mu \times 51 \mu$ and contained nine oval nuclei, several of which had distinct nucleoli. The specimen was taken from the pulmonary vein of a patient with carcinoma of the lung, about 10 minutes after rib resection.

Endothelial Cells.-Cells from the vascular endothelium are uncommon in white cell concentrates, but when they occur they can cause difficulty in identification. It is useful to make imprints of veins, arteries, and the chambers of the heart in order to study these cells, which show surprising variations such as forms with multiple or giant nuclei.

Typically, endothelial cells are found in sheets, and these have ragged edges with peripheral cells coming loose. Even when free from each other several are usually found close together (Fig. 14). The nuclei are oval, and a typical measurement would be $15 \mu \times 9 \mu$; the mean diameter of a single nucleus varies from $10 \mu$ to $14 \mu$ with rare exceptions above and below. The chromatin is rather denser than that of a monocyte, and there is often a small visible nucleolus. The cytoplasm is profuse and gives the impression of being torn and ragged at the edges. It stains pale blue and has a cloudy texture. Sometimes these cells are seen with pyknotic nuclei, or else with pink staining structureless nuclei which are obviously dead. A multinucleate form with pyknotic nuclei is shown in Fig. 15.
Tissue Mast Cells.-These are rarely seen in concentrates of circulating blood. They are exactly as described occurring in the bone marrow (Sandoz atlas), and one of them is shown in Fig. 16.

Erythropoietic Cells.-In three cases we have found in antecubital venous blood taken during operation small clumps of erythropoietic cells regarded as probable marrow emboli, since all three cases had had a rib resected from five to 10 minutes previously. In two cases there were 14 and 16 normoblasts respectively, and a central macrophage or reticulum cell (Fig. 17). The other case had four components lying near together in the same streak when the film was spread, with a total of 27 normoblasts, each fragment associated with a macrophage or a reticulum cell and one with an early megakaryocyte.

Trophoblastic Cells.-Douglas, Thomas, Carr, Cullen, and Morris (1959) have found mutlinucleate cells in blood from the broad ligament veins of pregnant women, especially early in pregnancy. The larger of these cells are very distinctive, and are believed to be wandering trophoblastic cells.

Mesothelial Cells. - In three samples of pulmonary vein blood we have found abundant cells of the type shown in Fig. 18. Comparison with the cells of pericardial fluid obtained during thoracic operations strongly suggests that these are free mesothelial cells accidentally included in the blood samples as a result of the needle traversing the pericardium. They are free cells of pericardial fluid rather than cells detached by the needle.

\section{Features of Malignant Cells}

The identification of malignant cells in any situation depends on two main characteristics. Firstly, the cells concerned must differ substantially from the other cell types found in that situation. In the case of white cell concentrates this requires a thorough knowledge of the cells of the blood including the more unusual ones described above. Secondly, the cells in question must correspond to the known appearance of malignant cells. As the cells of malignant tumours are extremely variable, so that it can almost be said that each tumour has a cell type unique to itself, the second criterion depends on a large experience of free malignant cells examined by the same technique.

At the best, the identification of a malignant cell on morphological grounds is only an opinion, and cannot be verified. The observer has to be constantly aware of his own fallibility. In the whole of our series, excluding leukaemia, myeloma, and 


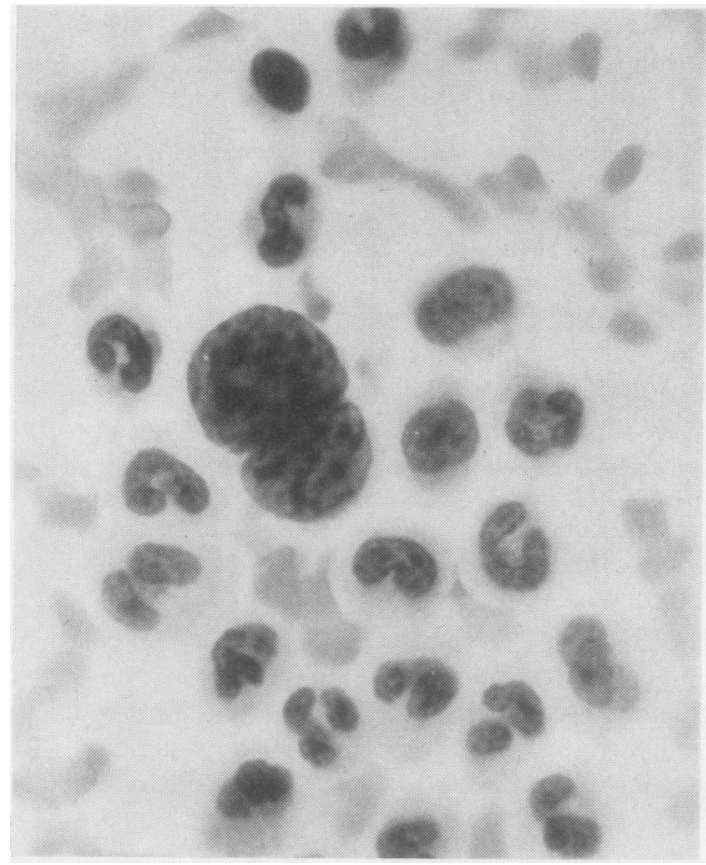

FIG. 5.-Megakaryocyte nucleus in a white cell concentrate fixed and stained by the Papanicolaou technique. Case of myelosclerosis $(\times 1,300)$.

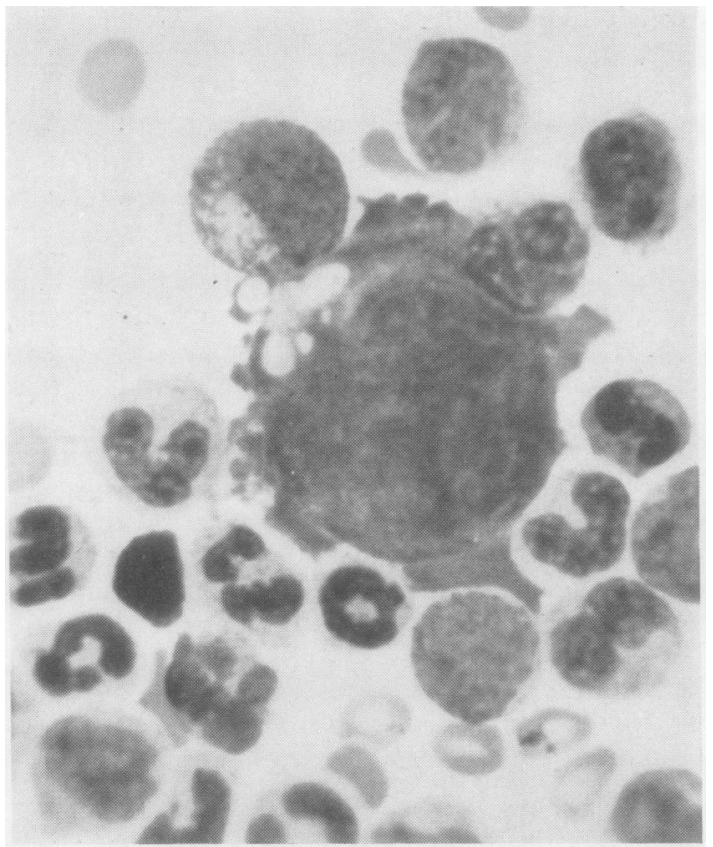

Fig. 7.-Megakaryoblast in the blood of a man of 51 with myelosclerosis. The cytoplasm was stained deep blue and showed no sign of the pink granulation which is present in mature megakaryocytes $(\times 1,300)$.

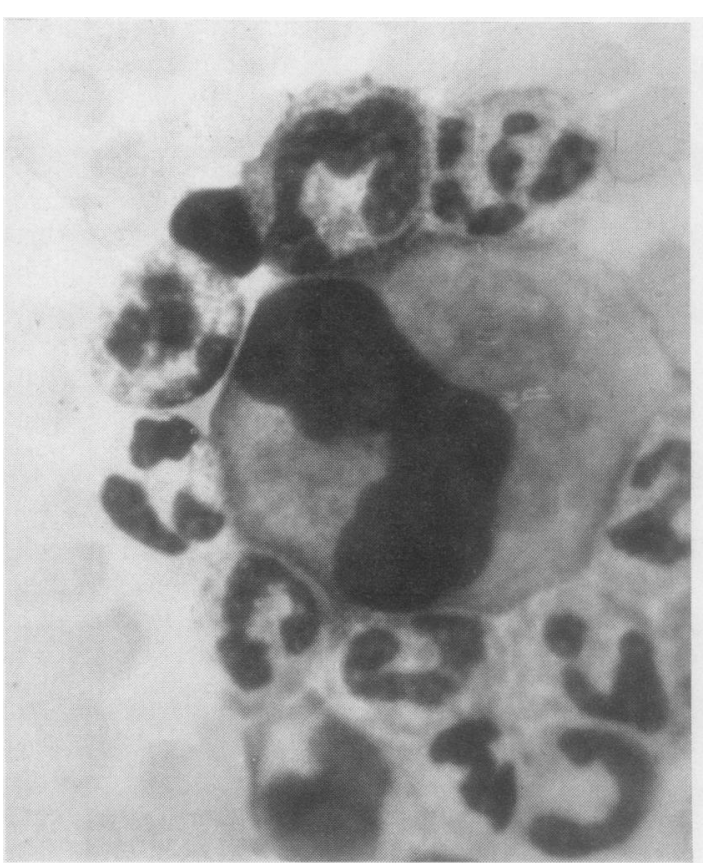

FIG. 6.-Complete megakaryocyte in the blood of a patient with $\varrho \vec{~}$ multiple myeloma. Megakaryocytes with complete cytoplasmo are much less common than the loose nuclei shown in Figs. $4 \leqq$ and $5(\times 1,300)$.

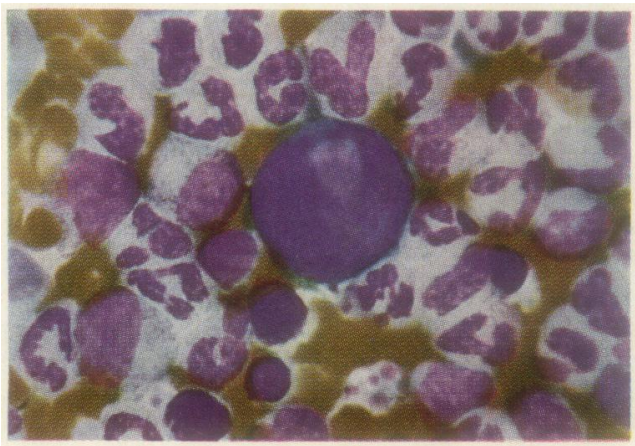

FIG. 8.-Another megakaryoblast from the same case as Fig. 7. Note the narrow rim of cytoplasm, which is more deeply basophilic than that of most tumour cells $(\times 485)$.

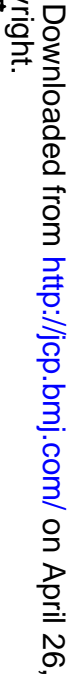

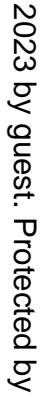




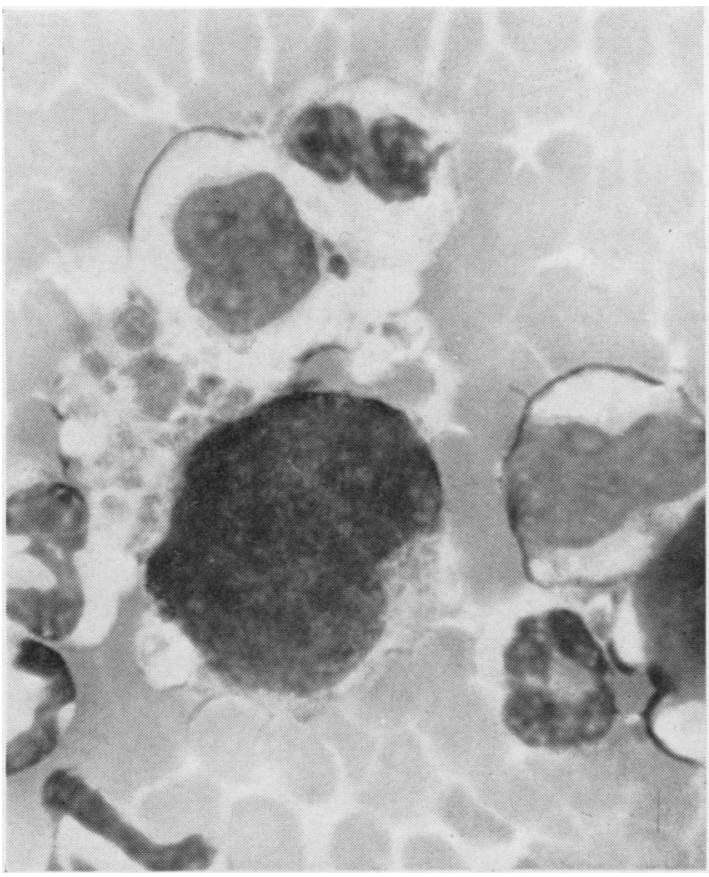

FiG. 9.-Immature megakaryocyte in the blood of a man aged 58 with myelosclerosis. This shows a group of adherent platelets $(\times 1,300)$.

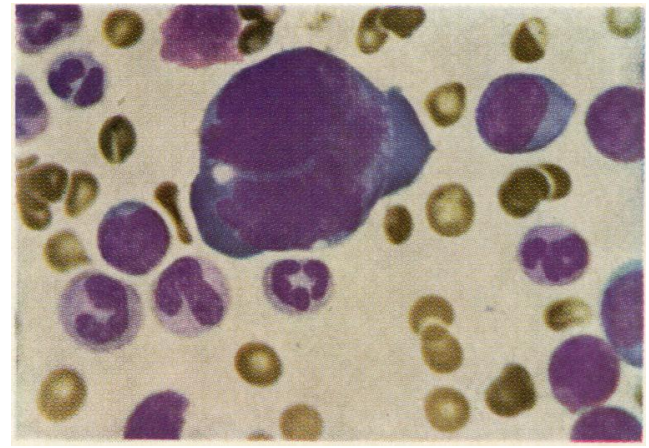

Fig. 11.-Immature megakaryocyte in the blood of a woman with myelosclerosis. Note the high nucleo-cytoplasmic ratio and dark blue cytoplasm $(\times 485)$.

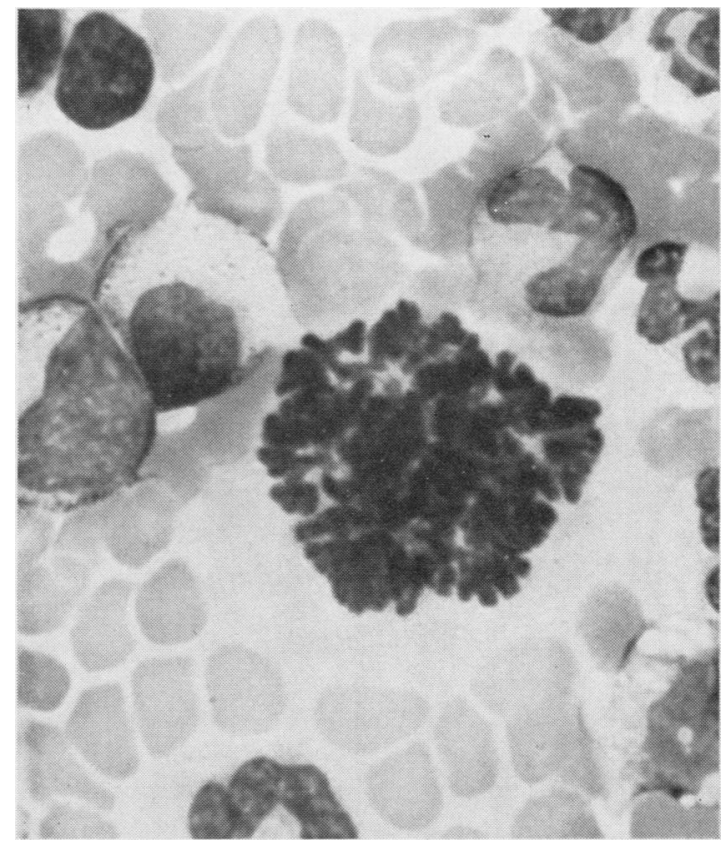

FIG. 10.-Same case as Fig. 9; a megakaryocyte is in mitosis (? multipolar) in the circulating blood $(\times 1,300)$.

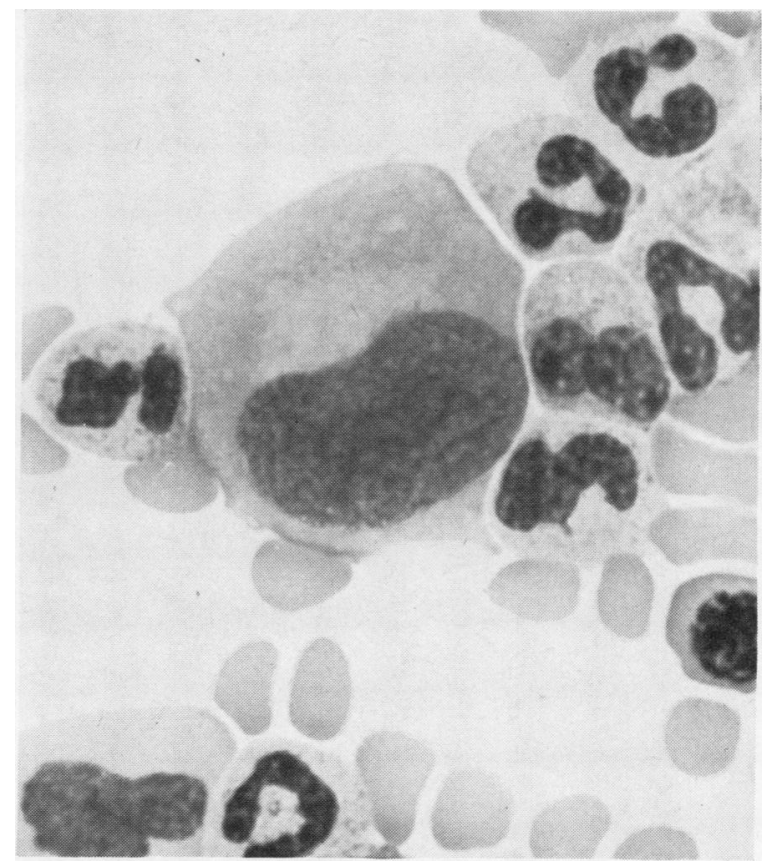

FiG. 12.-Unidentified cell from the same case as Figs. 7 and 8. This might belong to the megakaryocyte series. The patient did not have malignant disease $(\times 1,300)$. 


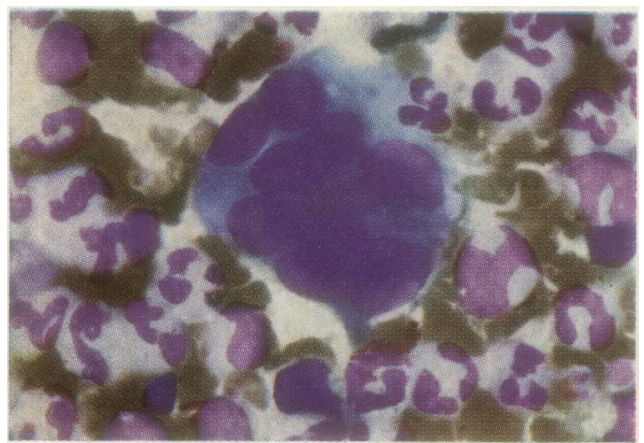

FIG. 13.-This cell is most probably an osteoclast. It comes from the pulmonary vein blood of a patient with carcinoma of the lung. Note the multiple uniform oval nuclei $(\times 485)$.

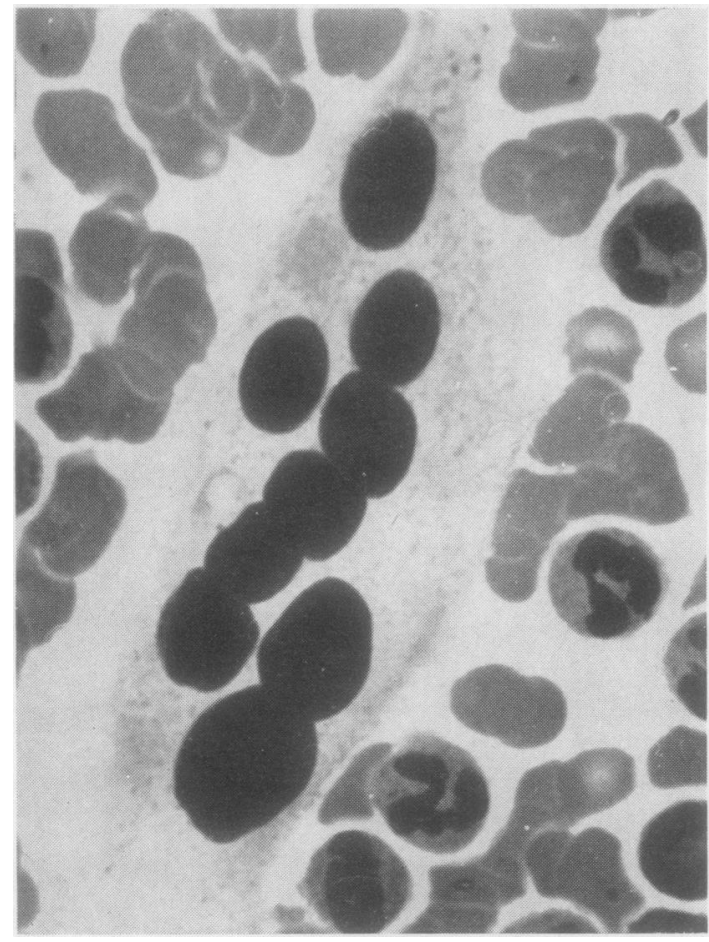

FIG. 15.-Multinucleate endothelial cell in venous blood. All the nuclei in this cell are pyknotic. Giant cells of this type can be found in smears made direct from vascular endothelium. Same case as Fig. $14(\times 1,300)$.

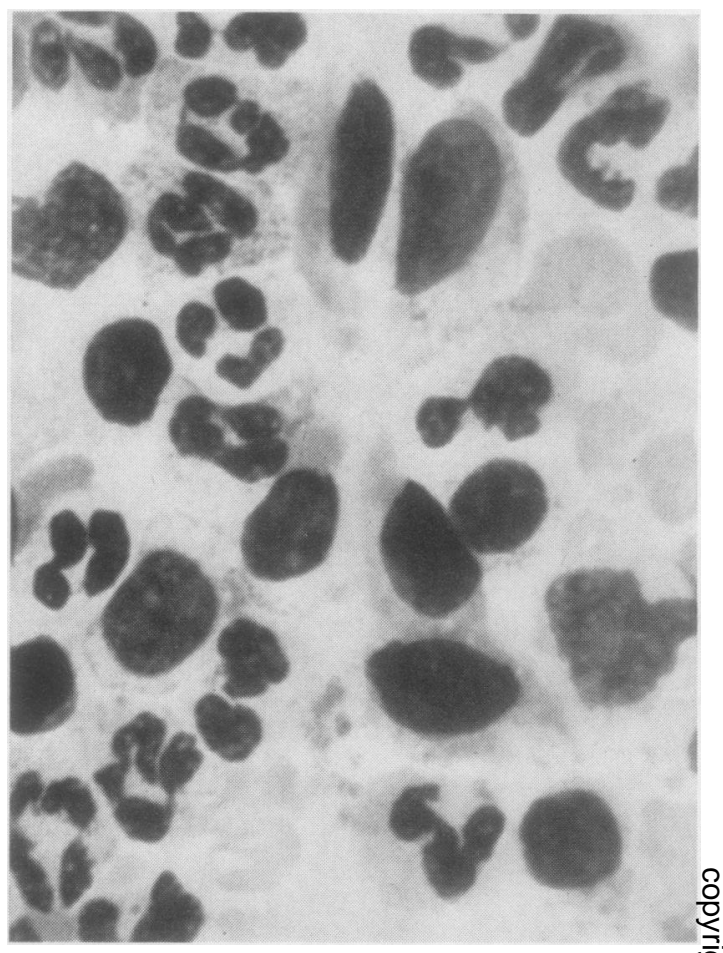

FIG. 14.-Endothelial cells, together with neutrophils and lymphocytes, in venous blood from a case of melanoma. The nucle $\vec{T}$ are elongated and the cytoplasm stains pale blue $(\times 1,300)$.

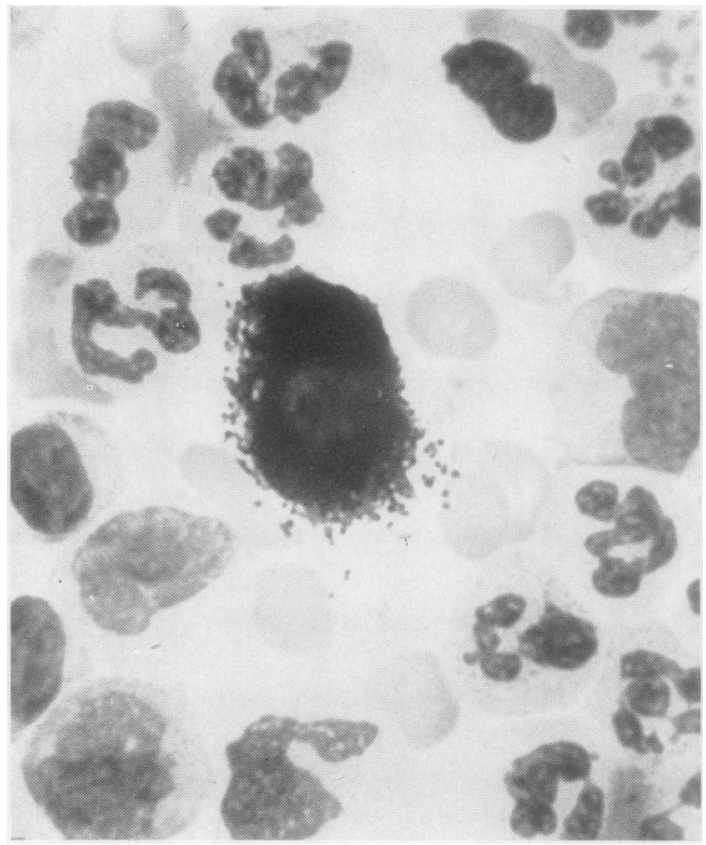

Fig. 16. - Tissue mast cell, from venous blood of a case of carcinoma of the lung $(\times 1,300)$. 


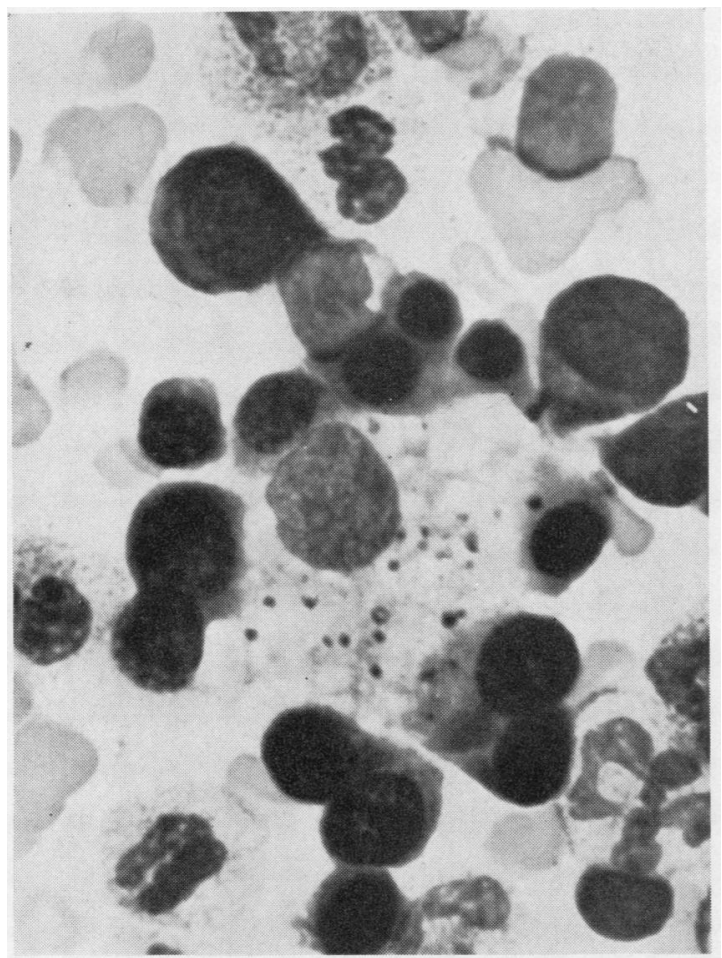

Fig. 17.-Erythropoietic embolus from antecubital venous blood of a patient with multiple myeloma (same case as Fig. 6). There is a central macrophage or reticulum cell containing pigment, surrounded by a ring of normoblasts $(\times 1,300)$.

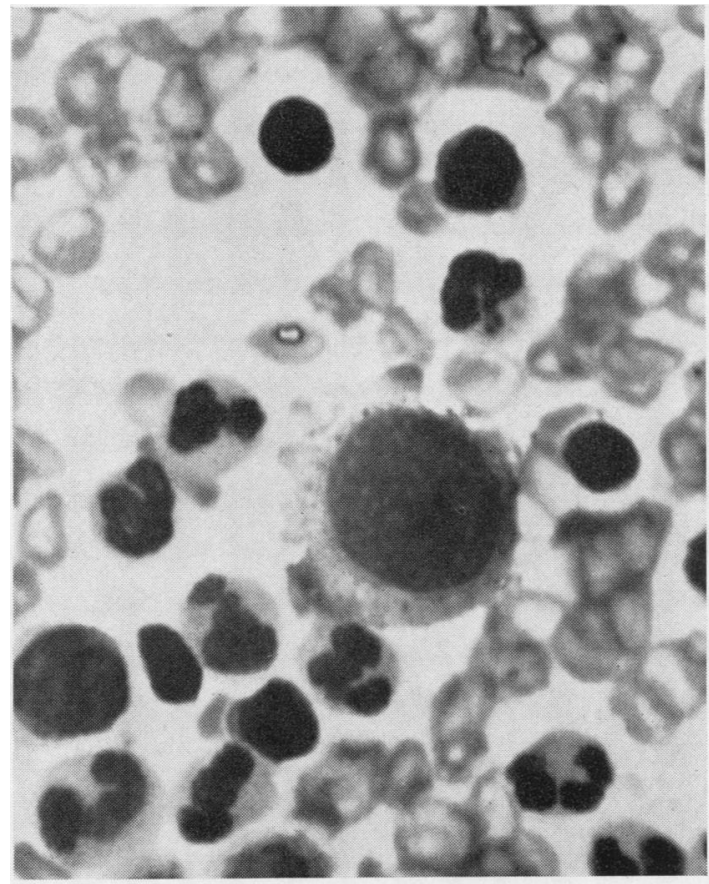

Fig. 19.-Tumour cell from a patient with malignant melanoma and multiple metastases (Case 1). This cell contained a small amount of fine melanin pigment. Similar cells were present in peritoneal fluid $(\times 1,300)$.

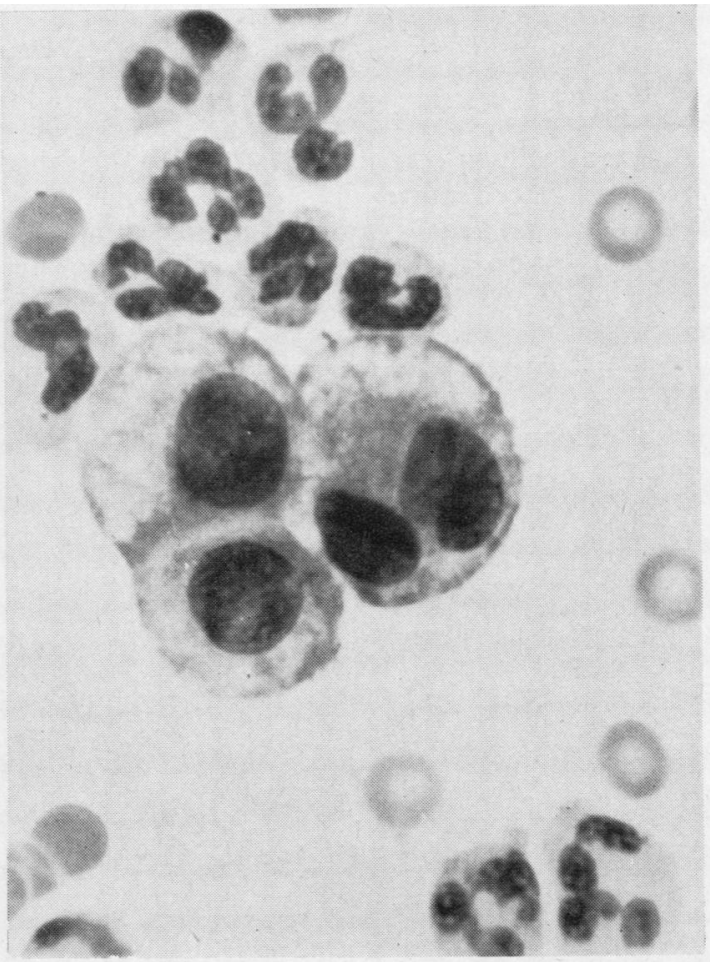

FIG. 18.-Mesothelial cells. The blood sample was obtained from the pulmonary vein of a patient with carcinoma of the lung. These cells were probably accidentally introduced, as the needle traversed the pericardium $(\times 1,300)$.

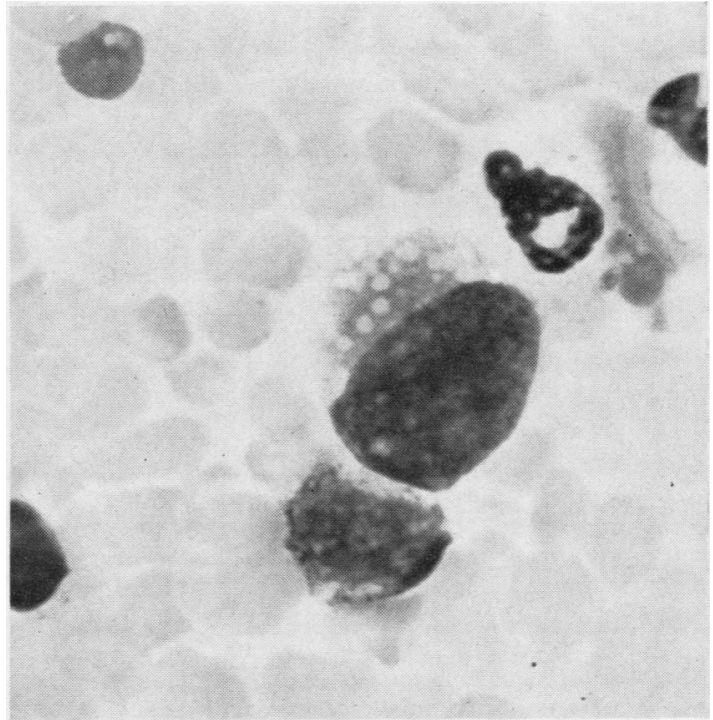

Fig. 20.-Tumour cell from a patient with malignant synovioma and widespread metastases (Case 2). Similar cells were found in bone marrow, pleural fluid, and cerebrospinal fluid $(\times 1,300)$. 
reticulosarcoma, we have only found acceptable malignant cells in seven cases. Two of these had extensive blood spread of sarcomas, a malignant synovioma and a malignant melanoma. Of the five cases of carcinoma, three had carcinoma of the bronchus, one of the breast, and one of the stomach. In the last, the specimen was obtained from a local vein, and in one of the cases of carcinoma of the bronchus the blood came from the pulmonary vein; otherwise all were venous samples from the arm.

The following are abbreviated case histories with descriptions of the cells.

\section{Illustrative Case Reports}

(1) Malignant Melanoma.-D. A. (Reg. No. 25563), a 33-year-old woman, with a pigmented malignant melanoma of the skin of the abdomen, at the time of finding tumour cells in the blood had hepatomegaly, anaemia, numerous scattered slate-blue spots, and melanuria. She died five months later, and multiple blood-borne metastases were found at necropsy.

The antecubital venous blood concentrate showed a few isolated tumour cells (Fig. 19) 22 to $28 \mu$ in diameter with nuclei 15 to $20 \mu$. The nuclei were central, round, with fine chromatin and blue nucleoli. The cytoplasm was pale blue and had irregular margins. Some cells contained small granules of pigment. There were also many macrophages with coarse melanin granules. (This case is described elsewhere in more detail by Goodall et al., 1960.)

(2) Malignant Synovioma.-P. A. (Reg. No. 9629), a 16-year-old girl, had a malignant synovioma which had been excised from the ulnar border of the hand 18 months previously. At the time of finding tumour cells in the blood she had lesions in the cervical and lumbar spine, the pelvis, and lymph nodes of the neck. There was a leuco-erythroblastic anaemia (haemoglobin $50 \%, 7.4 \mathrm{~g}$. per $100 \mathrm{ml}$.). Tumour cells were demonstrated in the cerebrospinal fluid, the marrow, and pleural fluid. She died 10 weeks later and necropsy confirmation was obtained. Tumour cells were fairly numerous in the antecubital venous blood concentrate and the cell illustrated (Fig. 20) was typical, measuring $26 \times 21 \mu$, and the nucleus $21 \times 15 \mu$. The nucleus was usually eccentric with slight irregularities and round clefts which stained pink, and had fine chromatin. The cytoplasm was of an opaque blue with a number of small vacuoles.

(3) Carcinoma of the Bronchus.-C. A. (Reg. No. 270081), a 66-year-old man, had had cough for nine weeks before thoracotomy, when an inoperable bronchial carcinoma was found. A mediastinal lymph-node biopsy showed anaplastic carcinoma, and tumour cells were found in the blood from an antecubital vein. $\mathrm{He}$ died three months later.

In the antecubital venous blood concentrate there was one clump of three tumour cells (Fig. 21), with diameters from 13 to $19 \mu$, showing a high nucleocytoplasmic ratio, irregularity, and mutual moulding

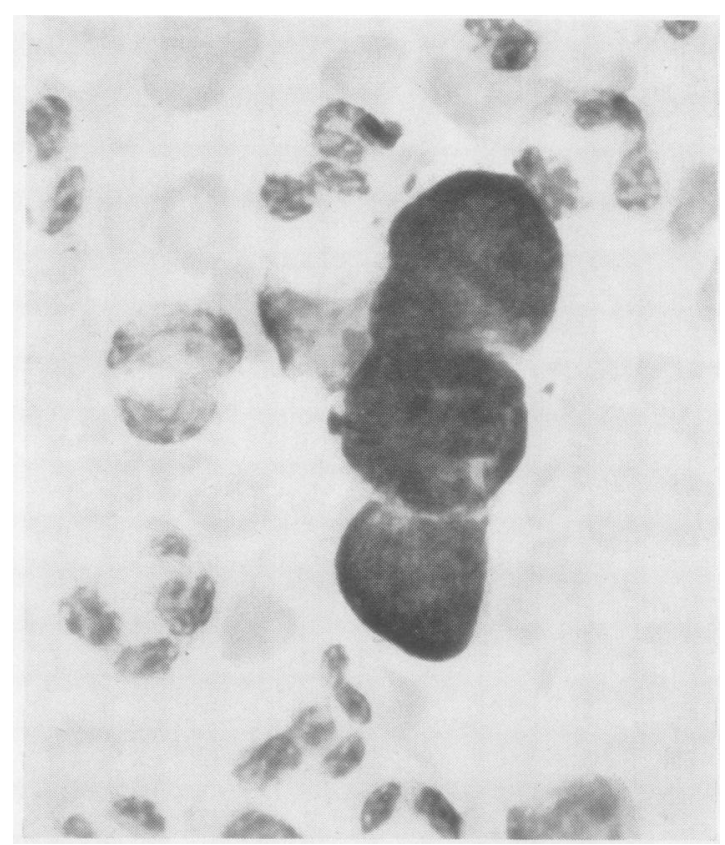

FIG. 21.-Malignant " oat-cells" from pulmonary vein blood in a case of carcinoma of the lung (Case 3$)(\times 1,300)$.

of the nuclei as is commonly seen in the "oat cells " illustrated by Spriggs (1957).

(4) Carcinoma of the Bronchus.-H. J. (Reg. No. 201020), a man aged 64 years, had had a stroke three months previously and pain in the chest one month before the finding of tumour cells in the blood. At that time he had a leuco-erythroblastic anaemia, a pleural effusion, hepatomegaly, jaundice, and a massive crop of small skin metastases which had developed in the previous 24 hours. He died three days later. Necropsy showed carcinoma of the right lower lobe bronchus, enlarged hilar nodes, and vertebrae riddled with deposits.

The antecubital venous blood concentrate showed a variety of abnormal cells. As well as the immature

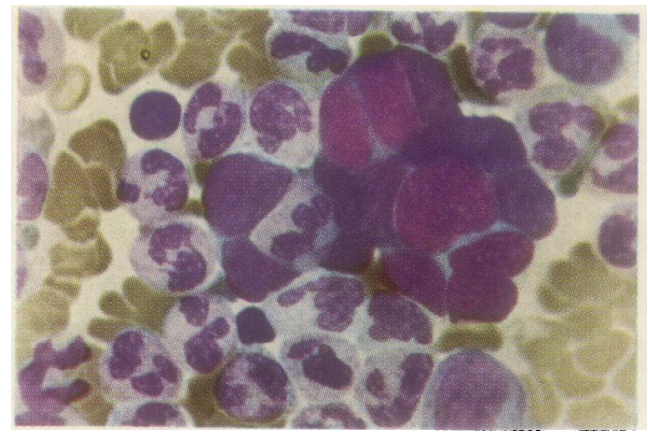

Fig.22.-Malignant "oat-cells" from antecubital venous blood of a patient with carcinoma of the lung and very numerous metastases (Case 4). Note the mutual compression of nuclei and scanty pale-staining cytoplasm $(\times \mathbf{4 8 5})$. 
haemopoietic cells, there were megakaryocytes or their bare nuclei, several macrophages, some containing pigment and a few containing two or three normoblasts at different stages of development, as well as unrecognizable pigmented material. The ingested normoblasts were well preserved. The macrophages varied from monocytes to larger cells with oval nuclei and profuse vacuolated cytoplasm sometimes finely dusted with eosinophilic matter. The variations and gradations from one type of cell to another were remarkable.

There were also numerous tumour cells, frequently in clumps of two or three and some up to 14 in number (Fig. 22). Single cells of similar appearance were present. The tumour cells were mostly 15 to $17 \mu$ in diameter, occasionally larger. The nuclei showed fine chromatin, a high nucleo-cytoplasmic ratio, and the mutual moulding of oat cells.

(5) Carcinoma of the Bronchus.-J. R. (Reg. No. 259099) was a 64-year-old man with carcinoma of the bronchus. The diagnosis was based on haemoptysis, the clinical findings, a lung shadow on radiographs, and the bronchoscopic findings. At the time of finding tumour cells in the blood he had headaches, neurological lesions, and superior vena caval obstruction. He died two weeks later. No biopsy or necropsy was obtained.

The antecubital venous blood concentrate showed five clumps of from four to eight tumour cells (Fig. 23).

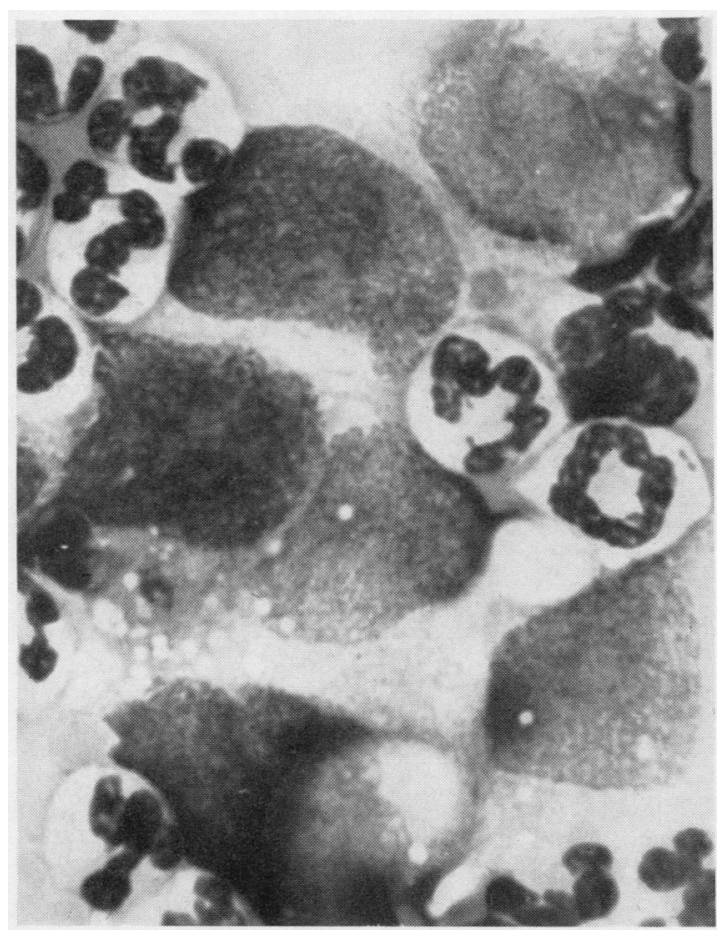

FIG. 23.-Anaplastic malignant cells from antecubital venous blood of a case of carcinoma of the lung (Case 5). These cells are larger than "oat-cells" and have a more profuse cytoplasm which stains pale blue-grey $(\times 1,300)$.
These measured about $30 \times 25 \mu$ but the cell margins were ill-defined. The irregular, angular nuclei measured 17 to $28 \mu$ in diameter. There were small separate nuclear fragments, the chromatin was finely punctate, and nucleoli were faintly seen. A few small vacuoles were present in the nuclei as well as the cytoplasm, which stained pale blue of varying density.

(6) Carcinoma of the Breast.-E. G. (Reg. No. 10270), a 36-year-old woman with scirrhous carcinoma of the breast, had had a radical mastectomy two and a quarter years previously. At the time of finding tumour cells in the blood she had diffuse bony metastases and a leuco-erythroblastic anaemia. Haemoglobin was $56 \%$ $(8.3 \mathrm{~g}$. per $100 \mathrm{ml}$.). Sternal marrow aspiration showed deposits of cells similar to those found in the peripheral blood. She died five months later.

The antecubital venous blood concentrate showed two rounded clumps and some single tumour cells. The larger clump had about 80 cells of $20 \mu$ diameter (Fig. 24). The oval or round nuclei varied in size from 10 to $15 \mu$, some having irregularities and several having blue nucleoli $3 \mu$ in diameter. The cytoplasm, of a finely granular blue, often showed no distinct cell margin.

(7) Carcinoma of the Stomach.-F. H. (Reg. No. 270542) a 59-year-old man with carcinoma of the stomach, had had symptoms for nine weeks before operation when tumour cells were found in the blood. Similar cells had been demonstrated in the gastric aspiration. Biopsy showed a poorly differentiated adenocarcinoma.

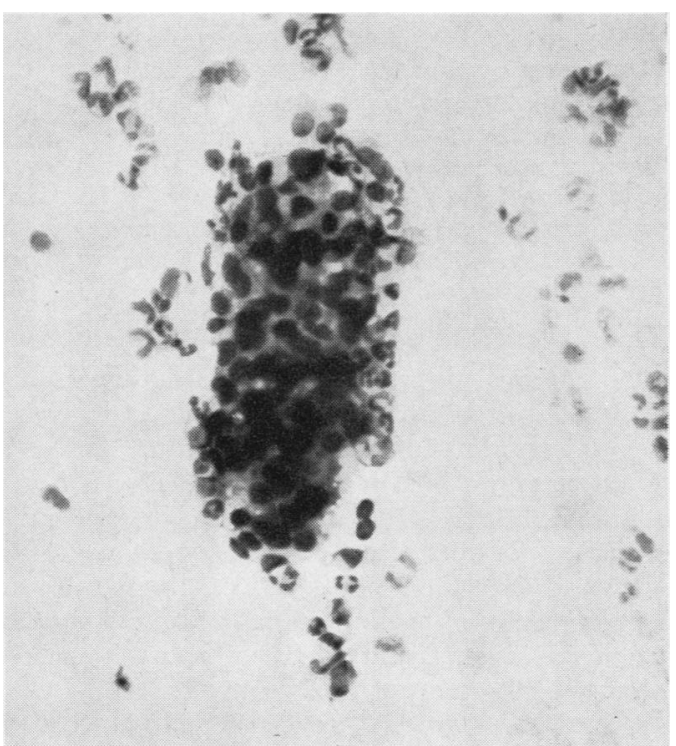

FIG. 24.-A cluster of tumour cells from antecubital venous blood of a case of carcinoma of the breast with widespread metastases. The cells occur in rounded clumps, unlike the ragged sheets formed by endothelial cells. Identical clumps were present in the bone marrow (Case 6) $(\times 260)$. 


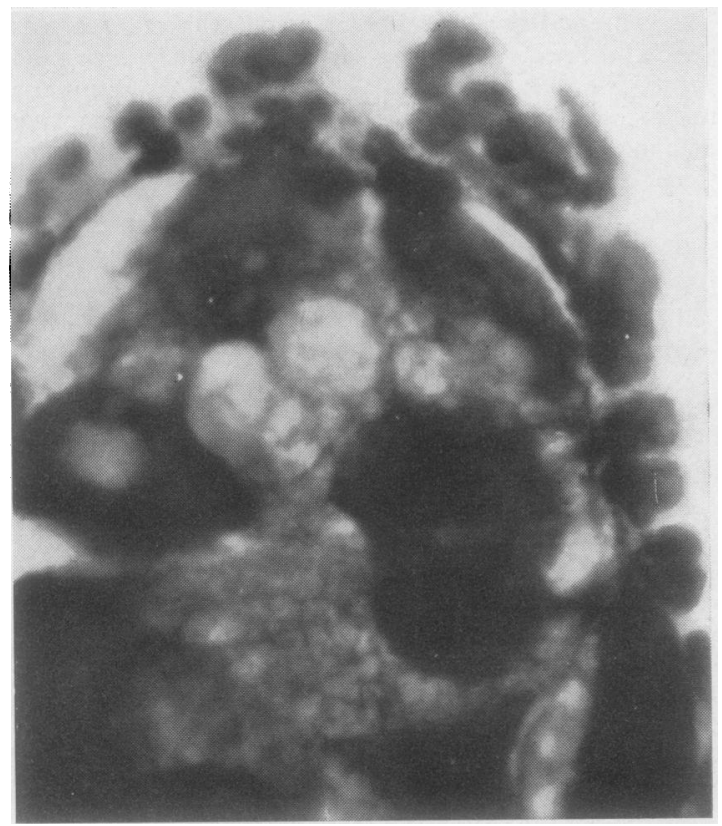

FIG. 25.-A collection of tumour cells from regional venous blood draining from a carcinoma of the stomach. A portion of the clump is shown, with a rounded edge. The cells composing the clump are distorted by vacuoles. Similar structures were found in gastric washings from this patient (Case 7$)(\times 1,300)$.

Death occurred four weeks later following pulmonary embolism from calf veins. Necropsy further demonstrated a large carcinomatous ulcer encircling the pylorus and tumour deposits in the gastric lymph nodes, the peritoneum, and the liver.

An omental venous blood sample showed several clumps of up to 12 tumour cells (Fig. 25). These cells were 30 to $40 \mu$ in diameter with irregularly shaped nuclei between 15 and $40 \mu$ across. Vacuolation with distortion of the cells was frequent.

\section{Conclusions}

Our findings confirm the fact that malignant cells can be recovered from circulating blood in certain cases of sarcoma and carcinoma. In this series there are seven cases in which such cells have been identified. None of the patients survived more than a few months after the first appearance of the cells, and we have failed to demonstrate any malignant cells in the blood of patients with operable carcinoma, even using samples from the venous drainage of the tumour.

Several other types of cell large enough to cause confusion with metastatic tumour cells are found occasionally or in small numbers in the blood. In normal healthy persons there are only a few mature megakaryocyte nuclei, and normal samples are therefore inadequate as control material from which to study the lesser known non-malignant cells.
Diseases accompanied by extramedullary blood formation, such as myelosclerosis, are an excellent source of puzzling cells, and we have illustrated megakaryoblasts from the peripheral blood of patients with this condition, which, if they had been seen in a case of advanced carcinoma, might well have been called malignant. Carcinomatosis, when it involves the skeleton, often causes a similar blood picture, and this can easily be a source of error.

Again, plasma cells and their precursors are well known to be increased in number in malignant disease, and it is necessary to be familiar with their variations.

Most of the unusual cells illustrated in the plates came, in fact, from cases of carcinoma, and it cannot be emphasized too strongly that histological proof of malignant disease on follow-up does not constitute sufficient proof that a "positive" cytological finding was correct. There is still room for further research into the non-malignant cells occurring in the circulation before statistical data on the frequency of circulating tumour cells can be considered accurate.

We are grateful to our colleagues of the United Oxford Hospitals who have kindly obtained samples of bloodo for this study; also to Dr. A. H. T. Robb-Smith for reading the manuscript and to $\mathrm{Mr}$. M. M. Boddingtonopo M.A., B.Sc., for help during the investigation and with the photographs. One of the authors (A. I. S.) gratefully acknowledges a grant from the British Empire Cancer Campaign.

\section{REFERENCES}

Bessis, M. (1956). Cytology of the Blood and Blood-forming Organs. Grune and Stratton, New York.

Christenson, W. N., Ultmann, J. E., and Mohos, S. C. (1956). Blood $11,273$.

Douglas, G. W., Thomas, L., Carr, M., Cullen, N. M., and Morris, R. (1959). Amer. J. Obstet. Gynec., 78, 960.

Engell, H. C. (1955). Acta chir. scand., Suppl. 201.

- (1959). Ann. Surg., 149, 457

Fisher, E. R., and Turnbull, R. B. (1955). Surg. Gynec. Obstet. 100,102 .

Fletcher, W. S., and Stewart, J. W. (1959). Brit. J. Cancer, 13, 33

Goodall, P., Spriggs, A. I., and Wells, F. R. (1960). Brit. J. Surg.

in press.
Guglielmo, G. di (1923). Haematologica, 4, 182.

Guglielmo, G. di (1923). Haematologica, 4,
Jonescu, P. (1931). Z. Krebsforsch., 33, 264.

Marcus, H. (1919). Ibid., 16, 217.

Moeschlin, S. (1947). Die Milzpunktion. Schwabe, Basel.

Moore, G. E., Sandberg, A., and Schubarg, J. R. (1957). Ann. Surg., 146,580 .

Nowell, P. C. (1960). Cancer Res., 20, 462.

Okinaka, S., Nakao, K., Kinugasa, K., Takaku, F., and Ohtsuki, K. (1956). Acta Haemat. jap., 19, 730.

Osgood, E. E., and Ashworth, C. M. (1937). Atlas of Hematology. Stacey, San Francisco.

Pool, E. H., and Dunlop, G. R. (1934). Amer. J. Cancer, $21,99$.

Pruit, J. C., Hilberg, A. W., and Kaiser, R. F. (1958). New Engl. J. Med., 259, 1161.

Reiss, R. (1959). J. Mt Sinai Hosp., 26, 171.

Roberts, S., Watne, A., McGrath, R., McGrew, E., and Cole, W. H. (1958). A.M.A. Arch. Surg., 76, 334.

Sand 1958). A.M.A. Arch. Surg., 76 Śchubarg, J. R. (1959). J. nat. Cancer Inst., 22, 555.

Spriggs, A. I. (1954). Thorax, 9, 26.

(1957). The Cytology of Effusions. Heinemann, London.

Tischendorf, W., and Heckner, F. (1950). Klin. Wschr., 28, 21

Undritz, E. (1948). Ann. paediat. (Basel), 171, 16.

Undritz, E. (1952). Sandoz Atlas of Haematology. 'Sandoz, Basel. 